INFINITY-Jurnal Matematika dan Aplikasinya (IJMA)

Volume 1 | Nomor 1 | Agustus | 2020

\title{
Pengklasifikasian Konsumsi Listrik Dengan Menggunakan Analisis Diskriminan Tiga Faktor di Kelurahan Penggoli Kecamatan Wara Utara Kota Palopo
}

\author{
Ewi Deanasari 1, Muhammad Muzaini' ${ }^{2}$, Dwi Risky Arifanti ${ }^{3}$
}

\author{
Corespondensi Author \\ IUniversitas Cokroaminoto Palopo, Fakultas \\ Sains, Palopo, Indonesia \\ 2Universitas Cokroaminoto Palopo, Fakultas \\ Sains, Palopo, Indonesia \\ 3IAIN Palopo, Fakultas Tarbiyah dan IImu \\ Keguruan, Palopo, Indonesia \\ 1[Email:ewideanasari24@gmail.com] \\ 2[Email:muhammadmuzaini@uncp.ac.id] \\ 3[Email:dwi risky arifanti@iainpalopo.ac.id]
}

Kata Kunci:

Konsumsi Listrik, Pengklasifikasian,

Analisis Diskriminan

\begin{abstract}
Abstrak. Penelitian ini bertujuan untuk memperoleh fungsi diskriminan tiga faktor yang terbentuk, untuk mengetahui perbedaan yang signifikan antara kategori penggunaan konsumsi listrik rendah, sedang, dan tinggi. Faktor yang mempengaruhi perbedaan penggunaan konsumsi listrik dan seberapa besar ketepatan hasil klasifikasi dari fungsi diskriminan. Variabel independen yang dianalisis dalam penelitian ini yaitu total barang elektronik $\left(X_{1}\right)$, jumlah anggota keluarga $\left(X_{2}\right)$, lama waktu di Rumah $\left(X_{3}\right)$, dan luas bangun rumah. Sedangkan variabel dependennya adalah kategori penggunaan konsumsi listrik $(Y)$, rendah, sedang, dan tinggi. Hasil analisis diskriminan tiga faktor, menunjukkan ada dua fungsi diskriminan yang terbentuk, yaitu ZScore $_{1}=-13.769+$ $0.205 X_{1}+0.76 X_{3} \quad$ dan $\quad$ ZScore $_{2}=7.392+$ $0.236 X_{1}-0.666 X_{3}$. Ada perbedaan yang signifikan antara kategori pengunaan konsumsi listrik rendah, sedang, dan tinggi. Variabel yang signifikan membedakan penggunaan konsumsi listrik adalah total barang elektronik, jumlah anggota keluarga, dan lama waktu di Rumah. Dalam pengujian validasi diperoleh angka ketepatan mengklasifikasi kasus sebesar $84 \%$, karena diatas $50 \%$, maka fungsi diskriminan yang terbentuk dianggap tepat untuk menggolongkan ketiga kategori penggunaan konsumsi listrik.
\end{abstract}

\section{PENDAHULUAN}

Peningkatan kapasitas energi listrik dapat dilihat seiring dengan kemajuan teknologi di berbagai aspek kehidupan. Energi listrik adalah salah satu energi yang paling diperlukan, sebab energi listrik mudah disalurkan serta mudah diubah dalam bentuk energi (Saleh, 2015). Kedudukan energi listrik sudah berubah seiring dengan perkembangan teknologi, energi listrik saat ini bukan hanya berperan sebagai kebutuhan kedua (sekunder) namun kini berperan sebagai kebutuhan pertama (primer), hal ini 
disebabkan karena listrik tidak bisa terlepas dari berbagai aktivitas yang dilakukan oleh setiap individu. Jika tidak ada istrik maka berbagai aktivitas individu akan sangat menghambat. Berbagai peralatan rumah tangga mulai dari kulkas, kipas angin, setrika, mixer, rice cooker sampai alat komunikasi seperti handphone, laptop dan berbagai macam media elektronik lainnya sangat memerlukan akan daya listrik. penggunaan energi ini adalah hal yang paling berpengaruh dalam kehidupan masyarakat serta menjadi hal tolak ukur dalam taraf kesejahteraan masyarakat. Banyaknya kebutuhan energi listrik akan sebanding dengan banyaknya penggunaan listrik yang dipakai (Yulia, 2018).

Setiap masyarakat harus bijak dalam menggunakan energi listrik, demikian juga perlu untuk mengetahui besarnya penggunaan konsumsi listrik karena jika listrik tidak digunakan dengan bijaksana tentunya akan berpengaruh terhadap besarnya persediaan listrik, keadaan ini akan berdampak pada berkurangnya persediaan listrik disebabkan penggunaan energi listrik lebih tinggi dibanding persediaan energi listrik (Saleh, 2015).

Analisis diskriminan merupakan teknik multivariat yang termasuk dalam dependence method, yaitu terdapat variabel dependen dan variabel independen dengan ciri variabel dependen harus berupa data kategori, sedangkan variabel independen berupa data non kategori. Analisis diskriminan mirip dengan analisis regresi, perbedaannya yaitu analisis regresi pada variabel dependennya justru harus data rasio, sedangkan jenis data untuk variabel independen dapat berupa data rasio atau kategori (Santoso, 2002).

Penelitian ini menggunakan analisis diskriminan tiga faktor (multiple discriminant analysis) untuk mengklasifikasikan penggunaan konsumsi listrik di Kelurahan Penggoli Kecamatan Wara Utara Kota Palopo. Variabel independen yang di analisis adalah total barang elektronik $\left(X_{1}\right)$, jumlah anggota keluarga $\left(X_{2}\right)$, lama waktu di Rumah $\left(X_{3}\right)$, dan luas bangun rumah. Sedangkan variabel dependennya adalah kategori penggunaan konsumsi listrik $(Y)$, rendah, sedang, dan tinggi. Penelitian ini bertujuan untuk memperoleh fungsi diskriminan tiga faktor yang terbentuk, untuk mengetahui perbedaan yang signifikan antara kategori penggunaan konsumsi listrik rendah, sedang, dan tinggi. Faktor-faktor yang membedakan penggunaan konsumsi listrik rendah, sedang, dan tinggi serta seberapa besar ketepatan hasil klasifikasi dari fungsi diskriminan.

\section{METODE}

Penelitian ini menggunakan jenis data primer, karena peneliti secara lansung mendaptkan data dari objek/responden yang di teliti. Pengertian data primer dan data sekunder adalah data yang bersumber dari objek/responden yang akan diteliti secara langsung, sedangkan data sekunder adalah data yang bersumber bukan dari objek/responden yang diteliti, melainkan melalui perantara (Indriantoro dan Supomo, 2013). Data yang akan yang diteliti pada penelitian ini adalah data penggunaan konsumsi listrik 50 responden masyarakat di Kelurahan Penggoli Kecamatan Wara Utara Kota Palopo, melalui metode wawancara dan metode dokumentasi.

Penelitian ini melalui beberapa tahapan, mulai dari pengumpulan data, kemudian dilanjutkan dengan proses analisis diskriminan yang menghasilkan model/fungsi diskriminan, selanjutnya tahap validasi, serta tahap terakhir yakni tahap interpretasi dan menarik kesimpulan. Untuk melakukan analisis diskriminan, maka dalam proses analisis peneliti menggunakan program SPSS.

\section{HASIL DAN PEMBAHASAN}

Berdasarkan hasil analisis diskriminan tiga faktor menggunakan software SPSS diperoleh hasil pada Tabel 1 berikut. 
Tabel 1. Tes Uji Variabel Rata-rata Kelompok

\begin{tabular}{lrrrrr}
\hline & \multicolumn{1}{c}{$\begin{array}{l}\text { Wilks' } \\
\text { Lambda }\end{array}$} & $F$ & $d f 1$ & $d f 2$ & Sig. \\
\hline $\begin{array}{l}\text { total barang } \\
\text { elektronik } \\
\text { jumlah anggota }\end{array}$ &, 385 & 37,475 & 2 & 47 &, 000 \\
$\begin{array}{l}\text { keluarga } \\
\text { lama waktu di }\end{array}$ &, 719 & 9,185 & 2 & 47 &, 000 \\
$\begin{array}{l}\text { Rumah } \\
\text { luas bangun Rumah }\end{array}$ &, 325 & 48,847 & 2 & 47 &, 000 \\
\hline Sumber &, 959 & 1,014 & 2 & 47 &, 371 \\
\hline
\end{tabular}

Sumber : Data sekunder setelah diolah (2020)

Kriteria pengujian untuk mengetahui perbedaan yang signifikan antara kategori penggunaan konsumsi listrik rendah, sedang, dan tinggi adalah sebagai berikut:

Jika Sig. $>0.05$ berarti tidak ada perbedaan antar kategori

Jika Sig. $<0.05$ berarti ada perbedaan antar kategori

Dapat diketahui bahwa dari empat variabel independen, ada tiga variabel independen yang memiliki perbedaan yang signifikan antara ketiga kategori penggunaan konsumsi listrik, yang telah sesuai dengan kriteria pengujian, varaibel independennya adalah: total barang elektronik $\left(X_{1}\right)$, jumlah anggota keluarga $\left(X_{2}\right)$, dan lama waktu di Rumah $\left(X_{3}\right)$. Hal ini berarti perilaku kelompok penggunaan konsumsi listrik rendah, penggunaan konsumsi listrik sedang, dan penggunaan konsumsi listrik tinggi, dipengaruhi oleh total barang elektronik, jumlah anggota keluarga, dan lama waktu di Rumah.

Akan tetapi, ketiga variabel independen tersebut, tidak dapat dipastikan apakah akan masuk kedalam fungsi diskriminan. Sehingga, pada proses analisis diskriminan semua variabel yang diteliti tetap diikutsertakan dalam analisis.

Tabel 2 dibawah ini untuk mengetahui variabel independen yang masuk ke dalam fungsi diskriminan.

Tabel 2. Variabel yang Masuk ke dalam Fungsi Diskriminan

\begin{tabular}{|c|c|c|c|c|c|c|c|}
\hline \multirow{3}{*}{ Step } & \multirow{3}{*}{ Entered } & \multicolumn{6}{|c|}{ Min. D Squared } \\
\hline & & \multirow{2}{*}{ Statistic } & \multirow{2}{*}{$\begin{array}{l}\text { Between } \\
\text { Groups }\end{array}$} & \multicolumn{4}{|c|}{ Exact $F$} \\
\hline & & & & Statistic & $d f 1$ & $d f 2$ & Sig. \\
\hline 1 & $\begin{array}{l}\text { lama waktu di } \\
\text { rumah }\end{array}$ & 2,234 & $\begin{array}{r}\text { rendah dan } \\
\text { sedang }\end{array}$ & 17,151 & 1 & 47,000 & ,000 \\
\hline 2 & $\begin{array}{l}\text { total barang } \\
\text { elektronik }\end{array}$ & 2,828 & $\begin{array}{r}\text { rendah dan } \\
\text { sedang }\end{array}$ & 10,625 & 2 & 46,000 & ,000 \\
\hline
\end{tabular}
mendiskriminasi antar kategori dan variabel yang membentuk fungsi diskriminan, yakni variabel total barang elektronik $\left(X_{1}\right)$ dan lama waktu di rumah $\left(X_{3}\right)$ ini:

Adapun proses pemasukan variabelnya dapat dilihat berdasarkan tabel 3 berikut

Tabel 3. Tes Wilk's Lambda

\begin{tabular}{lrrrrrrrrrr}
\hline Step & $\begin{array}{c}\text { Number of } \\
\text { Variables }\end{array}$ & \multirow{2}{*}{ Lambda } & \multirow{2}{*}{$d f 1$} & \multirow{2}{*}{$d f 2$} & & \multirow{2}{*}{$d f 3$} & \multicolumn{5}{c}{ Exact $F$} \\
\cline { 7 - 11 } & 1 &, 325 & 1 & 2 & 47 & 48,847 & 2 & 47,000 &, 000 \\
2 & 2 &, 210 & 2 & 2 & 47 & 27,219 & 4 & 92,000 &, 000 \\
\hline
\end{tabular}

Sumber: Data sekunder setelah diolah (2020) 
Tabel 3 menjelaskan bahwa langkah 1, hanya memasukkan satu variabel yakni lama waktu di rumah $\left(X_{3}\right)$ dimana skor Wilk's Lambda adalah 0.325 . Artinya, varians tidak bisa dijelaskan mengenai perbedaan antar kategori sebanyak 32.5\%. Selanjutnya, pada langkah 2 , ada dua variabel yang dimasukkan dalam analisis, dimana variabel total barang elektronik $\left(X_{1}\right)$ ditambahkan pada langkah 2, dengan skor Wilk's Lambda mengalami decrease, yaitu 0.21. Turunnya skor Wilk's Lambda, justru bernilai positif terhadap fungsi diskriminan, sebab varians yang tidak bisa dijelaskan makin rendah (langkah 1: 32.5\% dan mengalami decrease pada langkah 2: 21\%).

Dapat dilihat dari kolom Exact F dan kolom Sig., menunjukkan bahwa proses memasukkan variabel 1 dan variabel 2 dalam analisis terlihat baik, karena nilai signifikansi sesuai dengan kriteria analisis diskriminan, serta kedua variabel tersebut $\left(X_{1}\right.$ maupun $X_{3}$ ) memang berbeda untuk ketiga kelompok.

Untuk menguji perbedaan antar kategori dapat dilihat pada Tabel 4 berikut ini:

Tabel 4. Perbandingan Pasangan Kelompok

\begin{tabular}{|c|c|c|c|c|c|}
\hline \multirow{2}{*}{$\begin{array}{c}\text { Step } \\
1\end{array}$} & \multicolumn{2}{|c|}{$\begin{array}{l}\text { penggunaan konsumsi } \\
\text { listrik }\end{array}$} & \multirow[t]{2}{*}{ rendah } & \multirow{2}{*}{$\begin{array}{l}\text { sedang } \\
17,151\end{array}$} & tinggi \\
\hline & Rendah & $F$ & & & 95,078 \\
\hline & & Sig. & & ,000 &, 000 \\
\hline & Sedang & $F$ & 17,151 & & 33,761 \\
\hline & & Sig. & ,000 & & ,000 \\
\hline & Tinggi & $F$ & 95,078 & 33,761 & \\
\hline & & Sig. &, 000 & ,000 & \\
\hline 2 & Rendah & $F$ & & 10,625 & 78,703 \\
\hline & & Sig. & & ,000 & ,000 \\
\hline & Sedang & $F$ & 10,625 & & 35,615 \\
\hline & & Sig. &, 000 & &, 000 \\
\hline & Tinggi & $F$ & 78,703 & 35,615 & \\
\hline & & Sig. &, 000 &, 000 & \\
\hline
\end{tabular}

Sumber: Data sekunder setelah diolah (2020).

Pada Tabel 4 di atas menunjukkan jarak (distance) antara penggunaan konsumsi listrik rendah (kategori satu) dengan penggunaan konsumsi listrik tinggi (kategori tiga) merupakan jarak tertinggi, yaitu 78.703. Sebaliknya, jarak antara penggunaan konsumsi listrik sedang (kategori dua) dengan penggunaan konsumsi listrik rendah (kategori satu), merupakan jarak terendah, yakni 10.625.

Oleh karena itu, dapat dijelaskan bahwa penggunaan konsumsi listrik rendah paling berbeda (total barang elektronik dan lama waktu di rumah) dibandingkan dengan penggunaan konsumsi listrik yang masuk kedalam kategori penggunaan konsumsi listrik tinggi. Sebaliknya, penggunaan konsumsi listrik yang masuk kedalam kelompok penggunaan konsumsi listrik sedang memeiliki perbedaan (total barang elektronik dan lama waktu di rumah) yang sedikit dengan kategori penggunaan konsumsi listrik rendah.

Tabel 5. Ringkasan dari Fungsi Diskriminan

Nilai Eigen

\begin{tabular}{ccccc}
\hline Function & Eigenvalue & \% of Variance & Cumulative \% & Canonical Correlation \\
\hline 1 & $3,630^{\mathrm{a}}$ & 99,2 & 99,2 &, 885 \\
2 &, $030^{\mathrm{a}}$ &, 8 & 100,0 &, 170 \\
\hline
\end{tabular}


a. Fungsi diskriminan 2 digunakan pada analisis

Sumber: Data sekunder setelah diolah (2020).

Tabel 5 di atas menunjukkan bahwa kedekatan hubungan discriminant score dengan ketiga kategori penggunaan konsumsi listrik, dimana skala pengukuran kedekatan yaitu dari 0 sampai 1 . tertera angka 0.885 , hal ini berarti adanya hubungan yang lumayan besar. Sedangkan pada kolom Canonical Correlation, Function 2, tertera angka 0.17 , hal ini adanya hubungan yang lemah, akan tetapi fungsi kedua ini masih digunakan dalam interpretasi, hal ini sesuai dengan penjelasan "a" di bawah tabel 5.

Analisis dilanjutkan dengan menentukan fungsi diskriminan, yang hasilnya ditunjukkan pada tabel 6 berikut:

Tabel 6. Koefisien Fungsi Diskriminan

\begin{tabular}{|c|c|c|c|}
\hline & \multicolumn{2}{|c|}{ Function } & \multirow{5}{*}{$\begin{array}{l}\text { Keterangan: } \\
X_{1}=\text { total barang elektronik } \\
X_{3}=\text { lama waktu di rumah }\end{array}$} \\
\hline & 1 & 2 & \\
\hline \multirow{3}{*}{$\begin{array}{l}\text { Total barang } \\
\text { elektronik } \\
\text { Lama waktu di } \\
\text { rumah } \\
\text { (Constant) }\end{array}$} & 205 & 236 & \\
\hline & ,760 &,- 666 & \\
\hline & $-13,769$ & 7,392 & \\
\hline
\end{tabular}

Sumber: Data sekunder setelah diolah (2020).

Dari tabel 6 di atas, diperoleh koefisien fungsi diskriminan, sebagai beirkut: Fungsi diskriminan 1 (kolom function 1): $Z$ S core $_{1}=-13.769+0.205 X_{1}+0.76 X_{3}$ Fungsi diskriminan 2 (kolom function 2): $Z$ ZSore $_{2}=7.392+0.236 X_{1}-0.666 X_{3}$

Untuk menilai kelayakan model fungsi diskriminan yang telah dibentuk sebelumnya, maka selanjutnya dapat diketahui seberapa baik klasifikasi tersebut sudah tepat atau belum, atau seberapa persen terjadi missclasification pada proses klasifikasi tersebut. Tabel 7 dibawah ini akan menjelaskan hasil klasifikasinya:

Tabel 7. Hasil Klasifikasi

\begin{tabular}{|c|c|c|c|c|c|c|}
\hline & & \multirow{2}{*}{$\begin{array}{l}\text { Penggunaan } \\
\text { konsumsi } \\
\text { listrik }\end{array}$} & \multicolumn{3}{|c|}{$\begin{array}{l}\text { Predicted Group } \\
\text { Membership }\end{array}$} & \multirow[t]{2}{*}{ Total } \\
\hline & & & Rendah & Sedang & Tinggi & \\
\hline \multirow{6}{*}{ Original } & \multirow{3}{*}{ Count } & Rendah & 11 & 3 & 0 & 14 \\
\hline & & Sedang & 3 & 13 & 1 & 17 \\
\hline & & Tinggi & 0 & 1 & 18 & 19 \\
\hline & \multirow{3}{*}{$\%$} & Rendah & 78,6 & 21,4 & ,0 & 100,0 \\
\hline & & Sedang & 17,6 & 76,5 & 5,9 & 100,0 \\
\hline & & Tinggi & ,0 & 5,3 & 94,7 & 100,0 \\
\hline \multirow{6}{*}{$\begin{array}{l}\text { Cross- } \\
\text { validated }^{b}\end{array}$} & \multirow{3}{*}{ Count } & Rendah & 11 & 3 & 0 & 14 \\
\hline & & Sedang & 3 & 13 & 1 & 17 \\
\hline & & Tinggi & 0 & 1 & 18 & 19 \\
\hline & \multirow{3}{*}{$\%$} & Rendah & 78,6 & 21,4 & ,0 & 100,0 \\
\hline & & Sedang & 17,6 & 76,5 & 5,9 & 100,0 \\
\hline & & Tinggi & ,0 & 5,3 & 94,7 & 100,0 \\
\hline
\end{tabular}

a. 84,0\% kasus kelompok orisinil terklasifikasi dengan benar.

b. validasi silang dibuat hanya kasus-kasus dalam analisis tersebut, di dalam validasi silang.

c. $84,0 \%$ kasus kelompok validasi silang terklasifikasi dengan benar. 
Sumber: Data sekunder setelah diolah (2020).

Hasil validasi menunjukkan angka sebesar 84\%, berarti diatas 50\% maka fungsi diskriminan yang telah dibentuk "sudah layak" untuk membedakan ketiga kategori penggunaan konsumsi listrik tersebut..

\section{KESIMPULAN}

Berdasarkan hasil dan pembahasan, maka dapat diperoleh beberapa kesimpulan, yaitu:

1. Model/fungsi diskriminan yang dapat digunakan untuk mengkategorikan penggunaan konsumsi listrik yang masuk ke dalam ketiga kategori, adalah sebagai berikut:

Fungsi diskriminan 1: ZScore $_{1}=-13.769+0.205 X_{1}+0.76 X_{3}$

Fungsi diskriminan 2: ZScore $_{2}=7.392+0.236 X_{1}-0.666 X_{3}$

2. Ada perbedaan yang jelas antara responden yang masuk kedalam kelompok penggunaan konsumsi listrik rendah, responden kelompok penggunaan konsumsi listrik sedang, atau responden kelompok penggunaan konsumsi listrik tinggi.

3. Variabel yang membedakan penggunaan konsumsi listrik adalah total barang elektronik, jumlah anggota keluarga, dan lama waktu di Rumah.

4. Hasil validasi menunjukkan angka sebesar $84 \%$, berarti diatas $50 \%$ maka fungsi diskriminan yang telah dibentuk "sudah layak" untuk membedakan ketiga kategori penggunaan konsumsi listrik tersebut

Berdasarkan beberapa kesimpulan diatas, maka dapat diperoleh beberapa saran, yaitu:

1. Dalam penentuan besarnya penggunaan konsumsi listrik yang dikelompokkan dalam penggunaan konsumsi listrik rendah, penggunaan konsumsi listrik sedang, dan penggunaan konsumsi listrik tinggi, hendaknya bisa menambahkan variabel independen $(X)$ yang akan dianalisis dan sesuai dengan variabel dependen (penggunaan konsumsi listrik).

Model ini belum dapat digunakan sebagai generalisasi untuk seluruh wilayah di Kota Palopo, mengingat model yang diperoleh dalam penelitian ini menggunakan data primer penggunaan konsumsi listrik di Kelurahan Penggoli Kecamatan Wara Utara Kota Palopo. Untuk itu, dalam mencapai tingkat akurasi fungsi diskriminan yang baik, maka membutuhkan data yang lebih luas mencakup seluruh wilayah di Kota Palopo.

\section{REFERENSI}

Hasbi, M., Lukito, A., Sulaiman, R., \& Muzaini, M. (2019). Improving the Mathematical Connection Ability of Middle-School Students through Realistic Mathematics Approach. Journal of Mathematical Pedagogy (JoMP), 1(1), 37-46.

Muzaini, M., Juniati, D., \& Siswono, T. Y. (2018). Cognitive Style of File-dependent (FD): Quantitative Reasoning in Generalizing. Pancaran Pendidikan, 7(1).

Saleh, A. 2015. Implementasi Meode Klasifikasi Naïve Bayes Dalam Memprediksi Besarnya Penggunaan Listrik Rumah Tangga. Citec Journal, 2(3): 207-217.

Indriantoro, Nur dan Bambang Supomo. 2002. Meodologi penelitian bisnis untuk akutansi dan manajemen. BPFE. Yogyakarta.

Santoso, S. 2002. Buku latihan SPSS Statistika Multivariat. PT Elex Media Komptindo. Jakarta.

Yulia, Nurul Azwanti. 2018. Penerapan Algoritma C4.5 Untuk Memprediksi Besarnya Penggunaan Listrik Rumah Tangga di Kota Batam. Jurnal RESTI (Rekayasa Sistem dan Teknologi Informasi), 2(2): 584-590. 